\title{
Nota del editor
}

El año pasado, los juristas interesados en el derecho internacional humanitario rememoraron el sesquicentenario del nacimiento de Fjodor Fjodorovich Martens (1845-1909). La Redacción de la Revista se complace en publicar en este número un artículo de Vladimir Pustogarov sobre este famoso jurisconsulto de derecho internacional. El profesor Pustogarov es un conocido erudito ruso, que ha escrito, entre otras cosas, una biografía de Martens, disponible actualmente sólo en idioma ruso. La Redacción espera asimismo que la publicación de este artículo, ayude a intensificar las relaciones de la Revista con el mundo de habla rusa.

La Conferencia de Examen de la Convención de 1980 sobre Ciertas Armas Convencionales, cuyas sesiones se clausuraron el 3 de mayo de 1996, tuvo dos resultados concretos. En un primer artículo, Louise Doswald-Beck informa sobre la génesis y el alcance del nuevo Protocolo $I V$, por el que se prohibe el empleo de las armas que causan ceguera en la guerra: un resultado ciertamente satisfactorio. El informe de Peter Herby sobre la revisión del Protocolo II relativo a las minas versa sobre el resultado menos grato de la Conferencia. Como es sabido, los representantes de los países Partes en la Convención no lograron ponerse de acuerdo acerca de un texto satisfactorio. Seguimos, pues, careciendo de las bases jurídicas para una protección eficaz, especialmente de la población civil, contra la plaga de las minas.

En su artículo, Paul Berman describe la organización y las tareas del nuevo Servicio de Asesoramiento del CICR, otra medida más que debe contribuir a poner por obra las recomendaciones de la Conferencia para la Protección de las Víctimas de la Guerra, celebrada el año 1993, y cuya finalidad es potenciar la aplicación del derecho internacional humanitario en todos los conflictos armados.

Por último, la Revista tiene el penoso deber de anunciar la muerte violenta de tres colaboradores del Comité Internacional de la Cruz Roja. 
El 4 de junio de 1996, fue tiroteado en Burundi un convoy del CICR, y tres delegados, que habian ido a este martirizado país para dar testimonio de un poco de humanidad, perdieron la vida en el ataque. El CICR se ha visto obligado a interrumpir su acción humanitaria en Burundi, puesto que el emblema de la Cruz Roja ya no garantiza, evidentemente, la indispensable protección a sus delegados en sus actividades. Una triste comprobación, sin duda.

La Revista 